2017-12-10

The use of clickers in Instrumentation and Control Engineering Education: $\mathrm{A}$ Case Study

\author{
Khan, Asiya
}

http://hdl.handle.net/10026.1/10163

10.1080/03043797.2017.1405240

European Journal of Engineering Education

Taylor \& Francis

All content in PEARL is protected by copyright law. Author manuscripts are made available in accordance with publisher policies. Please cite only the published version using the details provided on the item record or document. In the absence of an open licence (e.g. Creative Commons), permissions for further reuse of content should be sought from the publisher or author. 


\section{The use of clickers in Instrumentation and Control Engineering education: a case study}

\section{Asiya Khan, Priska Schoenborn \& Sanjay Sharma}

To cite this article: Asiya Khan, Priska Schoenborn \& Sanjay Sharma (2017): The use of clickers in Instrumentation and Control Engineering education: a case study, European Journal of Engineering Education

To link to this article: http://dx.doi.org/10.1080/03043797.2017.1405240

$$
\text { Published online: } 16 \text { Nov } 2017 .
$$

Submit your article to this journal $\square$

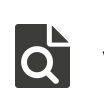

View related articles $\widetilde{ }$

View Crossmark data $\gtrsim$ 


\title{
The use of clickers in Instrumentation and Control Engineering education: a case study
}

\author{
Asiya Khan (1D) ${ }^{a}$, Priska Schoenborn ${ }^{b}$ and Sanjay Sharma ${ }^{a}$

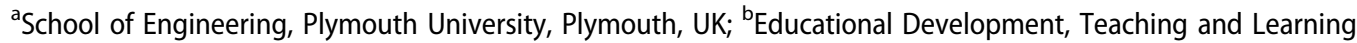 \\ Support, Plymouth University, Plymouth, UK
}

\begin{abstract}
This paper presents results from a small-scale study of third-year Instrumentation and Control Engineering $(n=37)$ at the University of Plymouth. The aim of the study was to enhance student learning and increase participation via the use of clickers. Clickers allow for student participation anonymously. The lecture content was modified to embed clicker questions at regular intervals to test knowledge, understanding and cognitive skills. Largely, the students preferred interactive lectures to traditional didactic lectures and using clickers increased student engagement and participation. Interestingly, compared to assessment results from the previous year, the increased level of engagement did seem to lead to an overall improvement in grades of approximately $10 \%$ in the subject of Control Engineering. However, in Instrumentation, the average fell by approximately $20 \%$. One possible contributory factor of this drop could be the changed exam format for Instrumentation only. This year, the multiple choice section was removed from the Instrumentation examination paper. Furthermore, an analysis of variance showed that in addition to using clickers in the lectures, attendance plays a key role. Results of this small-scale study show that for a more complex subject like Control, student learning, engagement and attainment can increase by the use of clickers.
\end{abstract}

\section{ARTICLE HISTORY}

Received 23 November 2016 Accepted 7 November 2017

\section{KEYWORDS}

Instrumentation and Control Engineering; clickers; engagement; participation

\section{Introduction}

Personal Response Systems or 'Clickers' are small hand-held devices that use turning point technologies on infra-red frequency to allow students to participate in a lecture in real time anonymously. The questions are usually in a multiple choice format. In Engineering there are a lot of facts and difficult concepts that need to be taught. Hence, the method of teaching is still predominantly didactic (Felder 2008). The content-heavy courses have been a continuous barrier to more widespread adoption of pedagogies of engagement such as active learning in Engineering (Demetry 2010). However, more recently there is a debate in engineering education towards active learning. A recent study in STEM subjects compared student attainment under traditional didactic teaching to active learning achieved by a combination of methods including the use of clickers (Freeman et al. 2014). Their study concluded that students taught by traditional lectures were 1.5 times more likely to fail as compared to those who were exposed to some form of active learning.

Clickers have been used by other academics (e.g. Rossiter 2014) to help identify the learning gaps in Control Engineering required as a pre-requisite for students to progress. Clickers have also been used in a Material Science course (Vernaza 2007) to check student understanding and improve 
their learning experience. Malandrino et al. (2014) propose a purpose-built quiz called Quiz Tool which is similar to clickers. Their tool works on the university intranet and avoids the cost of clickers. Clickers have been used in a group-based activity in a Geotechnical course which increased student participation and learning (Donohue 2014). A study in Physics (Crouch and Mazur 2001) showed that the use of peer instruction, which incorporates the use of clickers, not only improved the students' test scores on conceptual understanding but cognitive skills related to quantitative reasoning in problem situations (Brady, Seli, and Rosenthal 2013). Clickers represent an enabling tool to generate discussion over an answer by allowing everybody to participate. In a Mechanical Engineering course relating to complex structures, clicker quizzes improved student attainment (Lopez and Vinken 2013). A study in thermodynamics (Falconer 2007) highlighted as a result of using clickers the need to create screencasts to capture tutorial solutions and further explanation of concepts. More recently clickers along with a flipped classroom approach have been used in a study in a Fluid Mechanics course where student engagement and motivation increased; however, student grades did not improve (Lucke, Dunn, and Christie 2016).

Literature has shown that engineering education albeit sporadically is moving away from didactic to active teaching. For example, Twitter has been used to quiz students (Kim et al. 2015) and a video game has been developed to provide context to student learning (Coller and Scott 2009). Kirkwood and Price (2014) recommended to design the technology so that it enhanced learning and to measure that enhancement. Active learning engages students in the learning process (Prince 2004) and comes in many pedagogical forms such as group-based, project-based or problembased learning, flipped classroom and research-informed teaching to name a few. The emphasis here is in building on students' experience to engage them. Clickers are one way of introducing more 'active' forms of learning during traditional lectures. Using clickers breaks the monotony and draws the students into the topic under discussion.

Hence, the final-year BSc Instrumentation and Control module was developed to embed clicker questions to enhance student learning and participation. Another consideration, although outside of the scope of this paper, was to explore how such student data collected by the clicker software could potentially be used at the institutional level to inform decision-making and ultimately improve teaching and learning (Khan and Schoenborn 2016). The focus of this paper is on 'student engagement' which according to Harper and Quaye $(2009,5)$ is 'more than involvement or participation - it requires feelings and sense-making as well as activity'. In this study engagement is measured via student evaluation/feedback quizzes during the interactive lectures and by reporting student attainment in the examination. Historically, students have found Control Engineering very challenging. Therefore, the aim was to break it down using cognitive skill-based clicker questions with group work to facilitate the learning by increasing student engagement. Furthermore, student attendance was recorded for all the lectures as students routinely scan their university ID cards for this purpose.

\section{Clickers - advantages and disadvantages}

Clickers are small hand-held devices that allow students to participate in real time in a question posed by the lecturer. Research has shown several advantages of using clickers in teaching and learning. One advantage is that students can respond anonymously. This way they can participate without feeling embarrassed about making a mistake (Banks 2006; Durbin and Durbin 2006). However, a disadvantage of remaining anonymous is that it could lead to shy/introvert students not learning how to respond publicly and not gaining the confidence to explain the reasoning behind their response (Morgan 2008). One way to counteract that would be to split the class into groups before posing a question on clickers (Beatty 2004) and allocating time for peer discussions to take place. Peer discussion is a powerful method as it allows for deep meaningful cognitive processing that enhances student understanding of a concept and hence their learning (Smith et al. 2009). Group work can benefit quiet and introvert students as it exposes them to opposing arguments and logical processes 
of other group members (Morgan 2008) and clickers allow each individual student to respond giving them the opportunity to present their own views. Blasco-Arcas et al. (2013) found that the use of clickers enhanced active collaborative learning and engagement in social sciences. In addition, they established that interactivity with collaborative learning, where students were split into groups of 4-5 and were given time to discuss the question increased understanding. Another advantage as highlighted by Lantz (2010) is that students may cognitively organise lecture material as segregated concepts rather than as many interrelated concepts. Carefully designed clicker questions can act as the boundary linking the sections together. Most existing literature suggests that students are more engaged when clickers are used as they are actively involved in the learning process. However, more comprehensive qualitative research is needed (Kay and LeSage 2009) to explore this in detail.

Lectures have a place in higher education especially where teaching is content heavy. This has been one of the reasons why lectures are predominantly didactic in engineering education (Freeman et al. 2014). Clickers can break up the lectures by posing a question on the content just delivered or can be used as an assessment tool (Han and Finkelstein 2013) on the content delivered in prior weeks. It has been used in testing prior knowledge and misconceptions before the start of teaching to indicate to the lecturer where to pitch the teaching (Zhu, Bierwert, and Bayer 2007). Learning is the application of knowledge and questioning is integral to it. In a traditional lecture the questions are often met by silence or the same students respond. Clickers encourage all students to take part. It builds in a 'waiting time' where the lecturer is waiting for all to respond. This can be useful as it encourages everybody to take part in the activity.

A potential drawback of using technology in classrooms is that it may fail. However, it is the design of content that quizzes the pedagogy of learning. Therefore, should the technology fail, the questions are there to draw students out of their shell. While clickers can generate discussion on a topic that the majority of students misunderstand, their use can also result in less content being delivered. Therefore, it is necessary to add contingency, e.g. additional time/or use of other methods, such as podcasts, screencasts and Moodle quizzes to ensure that all content has been covered.

Another concern about the use of clickers sometimes voiced by students is that the questions are too easy (Zhu, Bierwert, and Bayer 2007). Student engagement declined when clickers were introduced according to Carnaghan and Webb (2007) in accounting education. They found that although student satisfaction and attainment increased marginally, it reduced creative asking of questions from the students. Also, not all students wanted to answer the clicker questions. If the focus is on technology rather than the pedagogy student interest can drop (Morgan 2008). Therefore, the challenge in using technology is the re-design of content by writing meaningful questions that challenge students and foster deep learning; questions that align with or assess the extent to which learning outcomes have been achieved so technology can play an effective part in enhancing the student experience and learning (Kirkwood and Price 2014). Instant feedback from students can enable the lecturer to adjust the pace of delivery and identify the knowledge deficiencies in the students.

Clickers should be seen as an enabler for learning and not a replacement. It is the pedagogy which is important. The clicker questions should be designed around the learning outcomes of the session. It is important to identify the aim of the questions, e.g. is it to test knowledge, stimulate cognitive processes or to promote articulation (Beatty et al. 2006). The aim of this study was to do all three. The knowledge-based questions were crafted around Instrumentation, the skill-based around Control and the responses triggered discussions - hence drawing students out and increasing participation.

Clicker questions were embedded at regular intervals to test both knowledge and skills. Figure 1 shows the question cycle (Beatty et al. 2006). All questions were written by taking into account the three main elements of the question cycle. Before - this is where the questions were designed based on the learning outcomes of the sessions and constructively aligned to the end-of-year assessment. During - this is where the students had the opportunity to digest the question and respond. For the Control questions peer learning took place at this stage, too. After - this is where the learning gaps were highlighted and discussion triggered. 


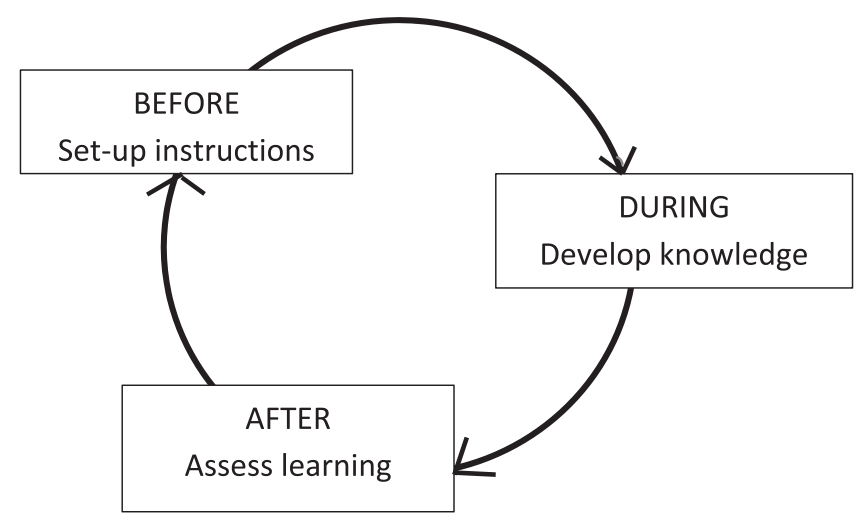

Figure 1. The question cycle (Beatty et al. 2006).

The subject of Instrumentation lends itself more easily to multiple-choice questions and allowed for continuous testing of knowledge; however, designing questions for the subject of Control was more challenging. Control questions were more skill-based, therefore, the problem was broken down into manageable chunks and peer work was facilitated before students responded to the clicker options. If the majority of the students responded to the question incorrectly, a discussion was initiated around the question. Once the students were comfortable with the correct answer, the same question was progressed to the next level. On the other hand, if the majority of students got it right, it also resulted in a brief discussion to ensure they chose the answer based on accurate knowledge and reasoning.

\section{Method}

This section presents the participant details, the procedures applied and the measures taken in this small-scale study.

\subsection{Participants}

A simple small-scale case study was conducted on an Instrumentation and Control module of a finalyear B.Sc. Mechanical Design and Manufacturing programme at the University of Plymouth. A total of 37 students were enrolled on the module. They were all males. The study was ethically approved by the Faculty of Science and Engineering at the University of Plymouth.

\subsection{Procedures}

Quantitative data were collected from clickers responses on student engagement and overall learning experience. This was carried out at two intervals - week 6 and week 13 of teaching weeks. In addition, an end-of-year student questionnaire was used and the student attainment results were analysed after the examination along with the attendance records.

\subsection{Measures}

The students have historically found the Control part of this module challenging. Therefore, the module content was re-written to embed clicker questions at regular intervals to achieve the following objectives: 
1. Improve student engagement and participation by making lectures active.

2. Improve the understanding of Instrumentation and test knowledge.

3. Improve understanding of Control as the majority of the students find it challenging.

4. Use peer learning with the Control questions

5. Enable students to improve their attainment in the examination.

6. Encourage better attendance

Historically, the module was taught in a didactic manner. The current lecturer took over in the previous academic year and initially, taught in a didactic manner where lectures were delivered first, followed by student tutorials. While the tutorials were more interactive, during lectures hardly anyone asked questions when prompted. This led to the motivation to use interactive methods such as 'clickers' to attempt to change the dynamics of teaching and learning. Apart from using clickers and associated activities during lectures, everything else remained the same as in the previous year. The assessment for Instrumentation was changed as recommended by the external examiner to remove the multiple-choice element, whereas, for Control, the assessment remained the same as in the previous year. The use of clickers made students more active throughout the duration of the module thus increasing participation and engagement which should result in deeper learning (Gibbs 1988).

\section{Results}

This section presents examples of the clicker questions posed to students in Instrumentation and Control. It further presents student responses from evaluation questions on their experience of interactive lectures captured during the last lectures for the particular subject, i.e. for Instrumentation, during week 6, and for Control, during week 12 . Student attainment results are presented also.

\subsection{Clicker questions and student evaluation responses}

Figure $2(a, b)$ show examples of Instrumentation questions and the student responses. Figure 2(a) shows that around $33 \%$ of the students responded correctly to a knowledge-based question covered earlier in the lecture. Similarly, Figure 2 (b) shows that $75 \%$ of the students responded to another question correctly. This resulted in discussion around understanding the concept of 'piezoelectric transducers' and 'strain gauges'. It also provided instant feedback to the lecturer.

Examples of Control questions are given in Figures 3 and 4 with student responses. Figure 3 shows an example of the testing understanding of Laplace Transform. $67 \%$ of the students responded correctly in the first polling. Figure 4 shows the challenge in questioning block diagram reduction in

MCQ2 - If a static force is applied to a piezoelectric transducer the electric charge generated will

A. increase over a period of time

B. remain static

C. decrease over a period of time

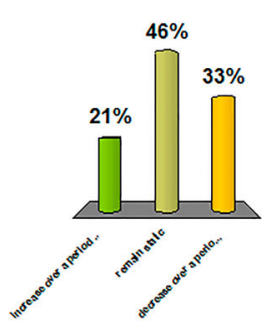

(a)

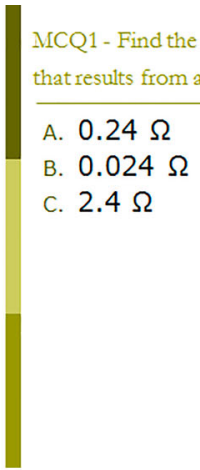

A. $0.24 \Omega$

B. $0.024 \Omega$

C. $2.4 \Omega$

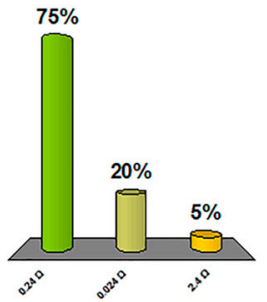

(b)

Figure 2. (a) Student responses to an Instrumentation clicker question. (b) Student responses to an Instrumentation clicker question. 


\section{$\mathrm{MCQ} 3-$ Find $\frac{X(s)}{F(s)}$, if $f(t)=5 \ddot{x}-2 \dot{x}+$ \\ $9 x$ assuming all initial conditions are zero}
A. $\frac{1}{5 s^{2}-2 s+9}$
B. $5 s^{2}-2 s+9$
C. $\frac{1}{5 s^{2}+2 s+9}$

$67 \%$

\section{$28 \%$}

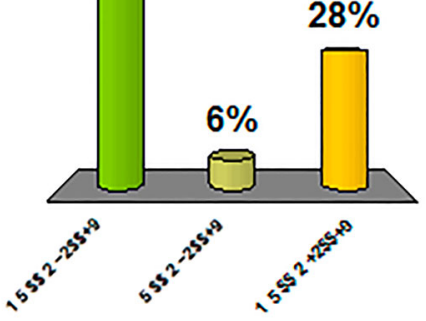

Figure 3. An example of a Control clicker question testing application of Laplace Transform.

Control. The problem is broken down into manageable chunks. Figure 4(a) presents the options to the first equation, Figure 4(b) shows options for the second equation and Figure 4(c) shows options for the overall transfer function. As can be seen from Figure 4(a), the majority of students' responses for the first equation were incorrect. However, most of them correctly identified the second equation as shown in Figure 4(b). This generated discussion before the final question on the transfer function was presented as shown in Figure 4(c).

At the end of teaching for both Instrumentation (week 6) and Control (week 12), some evaluative questions were posed to the students about their experience of using clickers and active learning. Table 1 summarises the questions and student responses.

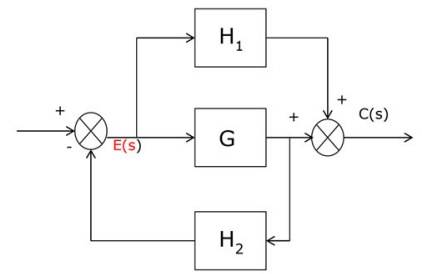

Step 1: write the equations

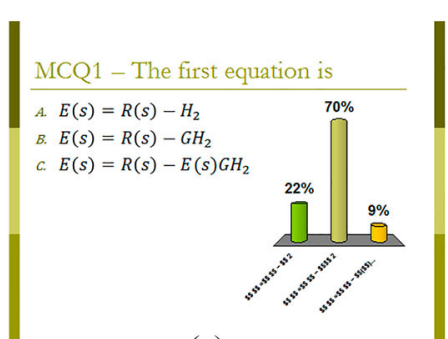

(a)

$$
\text { Find } \frac{C(s)}{R(s)}
$$

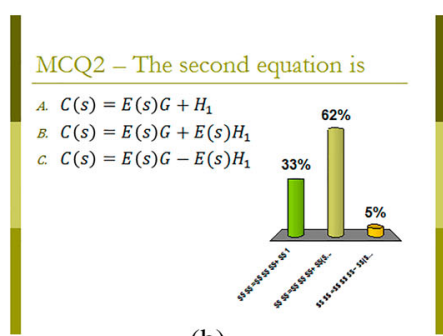

(b)

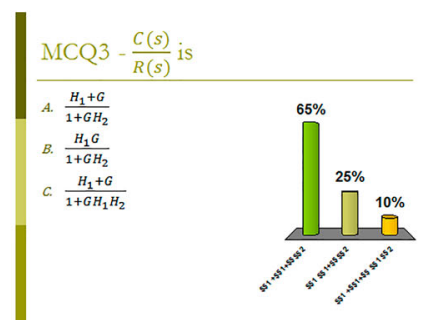

(c)

Figure 4. (a) Block diagram reduction Equation (1). (b) Block diagram reduction Equation (2). (c) Block diagram reduction transfer Function. 
Table 1. Report of example evaluation questions posed at weeks 6 and 12 .

\begin{tabular}{|c|c|c|c|}
\hline \multirow{8}{*}{$\begin{array}{l}\text { Questions posed at end of Instrumentation (week 6) } \\
n=26\end{array}$} & \multicolumn{3}{|c|}{ Did you prefer to have MCQs at relevant intervals to test knowledge? } \\
\hline & Yes $(95 \%)$ & No $(0 \%)$ & Not sure $(5 \%)$ \\
\hline & \multirow{2}{*}{\multicolumn{3}{|c|}{ Did you prefer a didactic method of teaching as opposed to interactive? }} \\
\hline & & & \\
\hline & \multicolumn{3}{|c|}{$\begin{array}{l}\text { Overall, how useful was the change in focus from lecture to interactive use } \\
\text { of 'clickers'? }\end{array}$} \\
\hline & $\begin{array}{l}\text { Very useful } \\
\text { (70\%) }\end{array}$ & $\begin{array}{l}\text { Made no difference } \\
(10 \%)\end{array}$ & Made some different (20\%) \\
\hline & \multicolumn{3}{|c|}{$\begin{array}{l}\text { Did you find the MCQs useful for reflection after the lecture in assisting you } \\
\text { with your studies? }\end{array}$} \\
\hline & Useful (53\%) & Not useful (5\%) & Not sure $(42 \%)$ \\
\hline \multirow[t]{6}{*}{ Questions posed at end of Control (week 12) $n=27$} & \multicolumn{3}{|c|}{$\begin{array}{l}\text { Was the use of clickers useful in understanding the mathematical part of } \\
\text { Control? }\end{array}$} \\
\hline & Yes $(82 \%)$ & No $(5 \%)$ & Sometimes (14\%) \\
\hline & \multicolumn{3}{|c|}{$\begin{array}{l}\text { Overall, in Control, how useful was it to change from a lecture style to } \\
\text { using clickers? }\end{array}$} \\
\hline & $\begin{array}{l}\text { Very useful } \\
\text { (70\%) }\end{array}$ & $\begin{array}{l}\text { Made no difference } \\
(10 \%)\end{array}$ & Made some difference (20\%) \\
\hline & \multicolumn{3}{|c|}{$\begin{array}{l}\text { How useful did you find the MCQs for reflection after the lecture in } \\
\text { assisting you with your studies? }\end{array}$} \\
\hline & Useful (66\%) & $\begin{array}{l}\text { Made no difference } \\
\quad(10 \%)\end{array}$ & $\begin{array}{l}\text { Have not started revising } \\
(24 \%)\end{array}$ \\
\hline
\end{tabular}

Table 1 shows that a majority of students (over 82\%) preferred clicker questions to test knowledge in Instrumentation and skills in Control. Also, $90 \%$ of students did not like the didactic method of teaching and around $90 \%$ students thought using clickers made a positive difference to their understanding of Control. The response to the last question in both Instrumentation and Control was about revising for the exams. After week $6,42 \%$ of students said they were not sure as they had not started revising. However, that number fell to $24 \%$ at the end of week 12 where still some students had not started revising for the exams.

In addition, responses from the end-of-year questionnaire indicate that around $82 \%$ of students felt the use of technology enhanced their learning experience.

\subsection{Student attainment}

The student attainment in the examination is compared to the previous year's examination results. In the previous year, the number of students was 29 , compared to 37 this year. The two-sample F-test was carried out to test the null hypothesis that the two marks (2015 and 2016) come from a distribution with the same variance. The returned value of $H=0$ indicates that the result does not reject the null hypothesis at the $5 \%$ significance level. The $p$-value was at .7235 which shows reasonable accuracy. Therefore, the comparison of students' attainment is carried out from 2015 to 2016 for both Instrumentation and Control.

Figure 5(a) shows a comparison of the Instrumentation marks. It is interesting that the overall attainment was reduced compared to the previous year. As this is a different cohort of students and the format of the examination changed from multiple choice to short questions, this comparison only serves to provide some information and as a basis for further exploration and discussion. In Control, a subject which is more cognitive skill-based, however, the overall student performance has improved compared to the previous year as shown in Figure 5(b). The exam format for this topic remained the same. Nevertheless, as for Instrumentation, the yearly cohorts differed and thus, only tentative conclusions can be drawn.

A more reliable comparison is that of student attendance and final assessment grades for both Control and Instrumentation in Figure 6(a,b).

There is a direct correlation with higher attainment linking to higher attendance as shown in Figure $6(a, b)$. However, that is more evident in Control (Figure 6(a)) than Instrumentation (Figure 6 


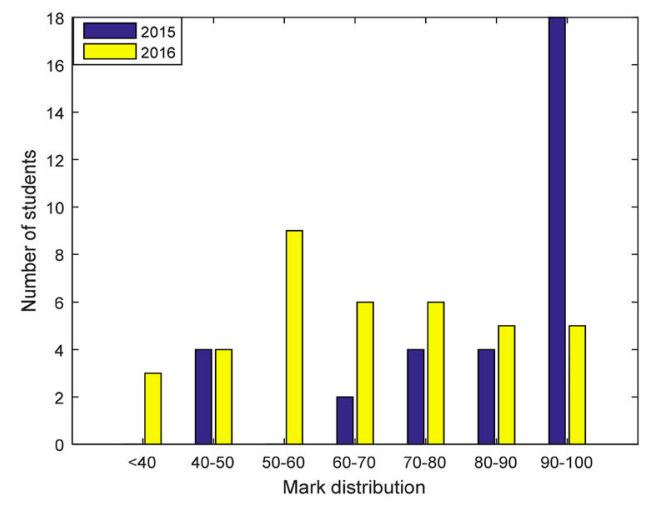

(a)

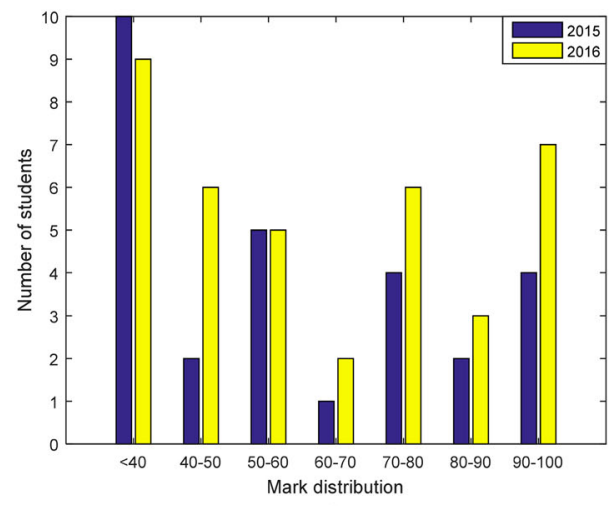

(b)

Figure 5. (a) A comparison of Instrumentation exam results from 2015 to 2016. (b) A comparison of Control exam results from 2015 to 2016.

(b)). There was one student with zero attendance who scored around 67\% in Instrumentation but 9\% in Control. Two students achieved high scores in Control with less than $10 \%$ attendance. This is an area of interest and will be investigated with further studies.

The marks and attendance distribution of the module are shown in Figure 7. The marks distribution in Control is from as low as $0 \%$ to $100 \%$. In Instrumentation, the lowest score is $16 \%$. The average mark in Instrumentation is around $68 \%$ and in Control $56 \%$ with an overall median of approximately $55 \%$. As can be seen, the overall Control mark has been improved by $10 \%$ compared to the previous cohort and from both the historic and current results, it is a subject area that the majority of students find challenging. Therefore, the data suggest that the use of interactive lectures has contributed to better understanding of concepts and that these were retained by the students. Although in Instrumentation the average mark fell by $20 \%$ from the previous cohort, a median mark of $68 \%$ is very good.

In addition, the relationship of Control marks with attendance on the overall marks of the students was analysed by performing two-way analysis of variance ANOVA) (Snedecor and Cochran 1989) to determine if the means in the overall marks differ when grouped by both factors (i.e. the impact of attendance on control marks). A two-way ANOVA between Control marks and attendance is shown in Table 2. The fourth column shows the $F$-statistic and the fifth column gives the $p$-value, which is derived from the cumulative distribution function (cdf) of $F$ (Snedecor and Cochran 1989). A small $p$ -

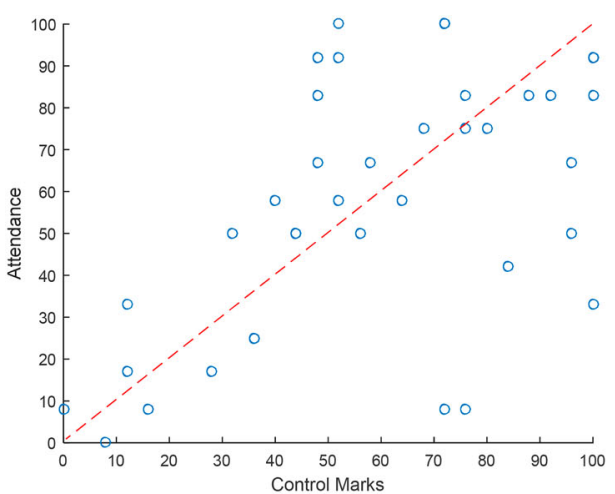

(a)

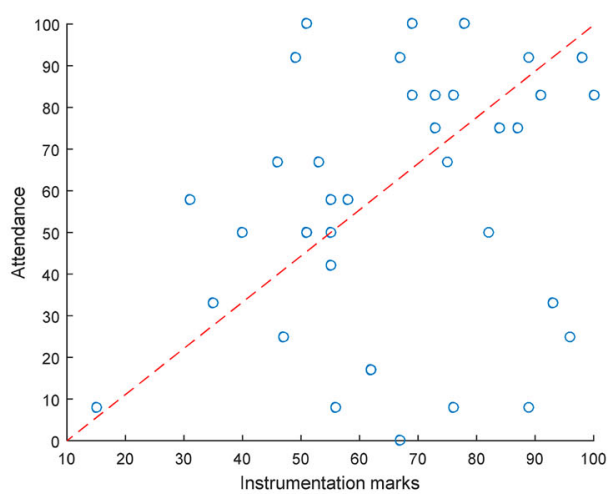

(b)

Figure 6. (a) Student attendance vs. Control marks for 2015-2016. (b) Student attendance vs. Instrumentation marks for 20152016. 


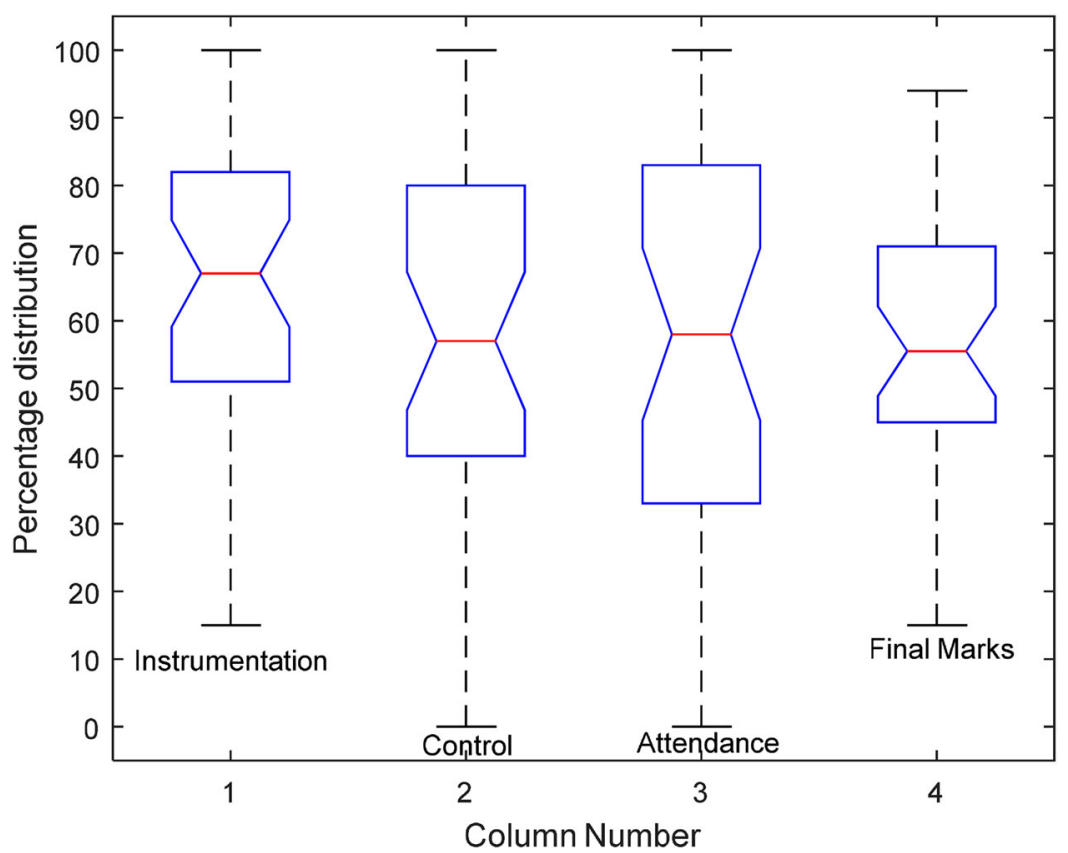

Figure 7. Box plot showing the marks and attendance distribution.

value indicates that overall marks are significantly affected by the corresponding parameter. Table 2 shows a higher $p$-value for attendance. However, when attendance impact is measured with the Control marks, the $p$-value is halved showing that the overall marks are affected by attendance.

\section{Discussions and limitations of the study}

The contribution of the paper is twofold. Firstly, student evaluation data suggest that interactive lectures can enhance student engagement and participation. Secondly, results indicate that in Control Engineering student participation as well as attainment improved with the use of clickers suggesting a possible link between increasing interactivity during lectures, increased participation and student attainment in a more challenging subject.

This small-scale study has shown that students prefer active learning over traditional didactic lectures. Student engagement and participation improved as a result of introducing clickers into the classroom; this also resulted in higher attainment in a more challenging subject material. However, the study has some limitations. In particular, the comparison in Instrumentation is unreliable as the cohorts as well as the exam papers differ. Similarly, the cohort in Control was different to the previous year. Moreover, formulating clicker questions for Control was more challenging for the tutor, which meant that more time and thought was spent on the design of the intervention and as a result, group work was used to generate discussions and peer support before clicker questions were initiated. This tentatively demonstrates that careful consideration of such interactive methods, using peer and tutor dialogue can lead to better understanding of more challenging

Table 2. Two-way ANOVA between Control marks and attendance.

\begin{tabular}{lccccc}
\hline Source & Sum of squares & Degree of freedom & Mean squares & F-statistics & $p$-Value \\
\hline Control marks & 5658.1 & 19 & 282.323 & 4.96 & .0656 \\
Attendance & 611.9 & 9 & 67.987 & 1.2 & .4649 \\
Control marks $\times$ Attendance & 268.9 & 2 & 134.435 & 2.36 & .2101 \\
\hline
\end{tabular}


subjects, encouraging problem-solving and resulting in higher levels of cognition which, in this study, seemed to benefit the students in the exams. However, in Instrumentation, which was more easily susceptible to the design of clicker questions that focus on memory and recall, the students responded individually and discussion was only generated after the response. These insights suggest that classroom methods that align and formatively build knowledge in line with summative assessment produce better results. The mismatch between exam and classroom methods in Instrumentation may have inhibited a more positive outcome.

A recent study by Lucke, Dunn, and Christie (2016) concludes that student engagement increases by using clickers. The results reported here are similar. Contrary to this study, Lucke who combined the use of clickers with the flipped classroom found that examination grades did not improve. In this study, however, examination grades for Control did improve although only preliminary conclusions can be drawn that the interactive use of clickers combined with group discussion had a positive effect on the exam results and further research is necessary to strengthen our initial findings. As the student cohort is different from the previous year, so are their characteristics and possibly, their educational abilities. The number of students has increased, also from 29 last year to 37 this year. Therefore, it is not possible to statistically verify the improvement in Control attainment. However, as the tutor intends to use clickers in future teaching, it will become more apparent what impact clickers have on the learning of the students. This is a further limitation of the study. Overall, the students enjoyed their learning experience echoing 'the use of clickers made a difficult concept easier to follow' and regular activities during lectures encouraged them to participate. They also found it broke the monotony of the lecture. For example, a general comment was 'most of us got it wrong' demonstrates that it gave them the confidence to vocalise the extent of their understanding.

Generally, better attendance equated to better attainment. However, there were some exceptions which will require further investigation. Did the students (with less than $30 \%$ attendance) forget to bring their University card? Did they study mainly from the material provided on the digital learning environment which includes all the Powerpoint files with clicker questions and solutions? The use of clickers led to an overall increase in attendance of $10 \%$ on average. The maximum attendance was around $80 \%$ and the minimum was around $60 \%$. This is an area of investigation for future studies to determine the reasons for not attending sessions and to improve practice to address this.

\section{Conclusions and future directions}

This paper presents results from a small-scale quantitative case study using clickers in Instrumentation and Control teaching at the University of Plymouth. Results show that a large majority of students $(>80 \%)$ prefer interactive lectures to didactic ones. Student engagement and participation improved as a result of interactive lectures. In addition, the attainment improved in Control demonstrated by a $10 \%$ increase in the class average compared to the previous year. However, the attainment in Instrumentation was reduced. This could be due to a number of contributory factors such as the different cohorts and the recent removal of a multiple-choice section from the Instrumentation exam paper. Another, that the subject content of Instrumentation lent itself more easily to the design of multiple choice clicker questions which focus on memory and recall. The design of clicker questions for Control, however, was more challenging and subsequently the questions focussed more on higher levels of cognition, encouraging problemsolving and peer discussion, thus, leading to a deeper learning experience. A direct correlation between attendance and attainment in Control which is more mathematical was found. A student with zero attendance achieved just under $70 \%$ in Instrumentation but failed the more challenging Control part achieving less than $10 \%$.

In the future, clickers will continue to be used, and Moodle quizzes will be developed specifically for teaching a large cohort of second-year students $(\sim 100)$. Further research will be carried out to strengthen the findings of this study. 


\section{Disclosure statement}

No potential conflict of interest was reported by the authors.

\section{Funding}

The work reported here is supported in part by the MSE-Small Grants (T \& L) Grant.

\section{Notes on contributors}

Dr Asiya Khan is a lecturer in Control Systems Engineering at the University of Plymouth and a member of the Autonomous Marine Systems Research Group. She received B.Eng. (Hons) in Electrical and Electronic Engineering from the University of Glasgow, M.Sc. in Communication, Control and Digital Signal Processing from Strathclyde University, Glasgow and Ph.D. in Multimedia Communication and Control from the University of Plymouth. She was awarded with the 'Best Paper Award' in ICAS 2009. Her research interest includes Control education pedagogies, intelligent control and wireless communications and control.

Ms Priska Schoenborn has been an Educational Developer at Plymouth University since 2007. For seven years prior she was a Lecturer in Computing. In addition to lecturing and supervising undergraduate students, she was an admissions tutor, stage tutor, placement tutor and partnership link tutor. Currently, Priska is a core tutor on the Postgraduate Certificate in Academic Practice. She also runs cross-institutional workshops, supports applicants in gaining fellowship with the Higher Education Academy and manages the internal pre-selection process for the National Teaching Fellowship Scheme. Priska is a National Teaching Fellow, Senior Fellow of the Higher Education Academy (SFHEA) and HEA accreditor.

Associate Professor Sanjay Sharma is a Reader in the School of Marine Science and Engineering at the University of Plymouth and is Head of the Autonomous Marine Systems (AMS) Research Group. He completed his B.Tech. (Hons) in Electrical Engineering from Indian Institute of Technology, Kharagpur (IITKGP), M.Tech. (Hons) in Control Systems from Institute of Technology - BHU, India and Ph.D. in Control and Systems Engineering from University of Sheffield, UK. $\mathrm{He}$ is a member of the IMechE's Marine, Informatics and Control group (MICG) and also a member of the IFAC Technical Committee on Intelligent Autonomous Vehicles.

\section{ORCID}

Asiya Khan (D) http://orcid.org/0000-0003-3620-3048

\section{References}

Banks, D. A. 2006. "Reflections on the Use of ARS with Small Groups." In Audience Response Systems in Higher Education, edited by D. A. Banks, 373-386. Hershey, PA: Information Science.

Beatty, I. 2004. "Transforming Student Learning with Classroom Communication Systems." EDUCAUSE Research Bulletin 2004 (3): 1-13.

Beatty, I., W. Gerace, W. Leonard, and R. Dufresne. 2006. “Designing Effective Questions for Classroom Response System Teaching." American Journal of Physics 74 (1), January: 31-39.

Blasco-Arcas, L., I. Buil, B. Hernández-Ortega, and F. J. Sese. 2013. "Using Clickers in Class. The Role of Interactivity, Active Collaborative Learning and Engagement in Learning Performance." Computers \& Education 62: 102-110.

Brady, M., H. Seli, and J. Rosenthal. 2013. "Clickers and Metacognition: A Quasi-experimental Comparative Study about Metacognitive Self-regulation and Use of Electronic Feedback Devices." Computers \& Education 65: 56-63.

Carnaghan, C., and A. Webb. 2007. "Investigating the Effects of Group Response Systems on Student Satisfaction, Learning, and Engagement in Accounting Education." Issues in Accounting Education 22 (3): 391-409.

Coller, B., and M. Scott. 2009. "Effectiveness of Using a Video Game to Teach a Course in Mechanical Engineering." Computers \& Education 53: 900-912.

Crouch, C. H., and E. Mazur. 2001. "Peer Instruction: Ten Years of Experience and Results." American Journal of Physics 69 (9): 970-977.

Demetry, C. 2010. "Work in Progress - An Innovation Merging 'Classroom Flip' and Team-Based Learning." Paper presented at 40th ASEE/IEEE Frontiers in education conference, Washington, DC, October 27-30.

Donohue, S. 2014. "Supporting Active Learning in an Undergraduate Geotechnical Engineering Course Using Groupbased Audience Response Systems Quizzes." European Journal of Engineering Education 39 (1): 45-54.

Durbin, S. M., and K. A. Durbin. 2006. "Anonymous Polling in a Engineering Tutorial Environment: A Case Study"." In Audience Response Systems in Higher Education, edited by D. A. Banks, 116-126. Hershey, PA: Information Science.

Falconer, J. 2007. "Concept Tests for a Thermodynamics Course." Chemical Engineering Education 41 (2): 107-114. 
Felder, R. 2008. "Engineering Education: A Tale of Two Paradigms." Decision Sciences Journal of Innovative Education 6 (1): 1-10.

Freeman, S., S. Eddy, M. McDonough, M. Smith, N. Okoroafor, H. Jordt, and M. Wenderoth. 2014. "Active Learning Increases Student Performance in Science, Engineering and Mathematics." Proceedings of the National Academy of Sciences 111 (23): 8410-8415.

Gibbs, G. 1988. Learning by Doing: A Guide to Teaching and Learning Methods. Oxford: Oxford Further Education Unit.

Han, J., and A. Finkelstein. 2013. "Understanding the Effects of Professors' Pedagogical Development with Clicker Assessment and Feedback Technologies and the Impact on Students' Engagement and Learning in Higher Education." Computers \& Education 65: 64-76.

Harper, S. R., and S. J. Quaye, eds. 2009. Student Engagement in Higher Education. New York: Routledge.

Kay, R. H., and A. LeSage. 2009. "Examining the Benefits and Challenges of Using Audience Response Systems: A Review of the Literature." Computers \& Education 53: 819-827.

Khan, A., and P. Schoenborn. 2016. "Measuring Student Engagement and Participation: How Can an Engineering Lecturer's Use of Technology in Teaching and Learning Contribute Towards Institutional Research?" Heir Conference, Liverpool John Moores University, September 7-8.

Kim, Y., S. Jeong, Y. Ji, S. Lee, K. Kwon, and J. Jeon. 2015. "Smartphone Response System Using Twitter to Enable Effective Interaction and Improve Engagement in Large Classrooms." IEEE Transactions on Education 58 (2): 98-103.

Kirkwood, A., and L. Price. 2014. "Technology-enhanced Learning and Teaching in Higher Education: What is 'Enhanced' and How Do We Know? A Critical Literature Review." Learning, Media and Technology 39 (1): 6-36.

Lantz, M. 2010. "The Use of 'Clickers' in the Classroom: Teaching Innovation or Merely an Amusing Novelty?" Computers in Human Behavior 26 (4): 556-561.

Lopez, I., and E. Vinken. 2013. “Example of Good Practice of a Learning Environment with a Classroom Response System in a Mechanical Engineering Bachelor Course." European Journal of Engineering Education 38 (6): 652-660.

Lucke, T., P. Dunn, and M. Christie. 2016. "Activating Learning in Engineering Education Using ICT and the Concept of 'Flipping the Classroom'." European Journal of Engineering Education 42: 1-13.

Malandrino, D., I. Manno, G. Palmieri, V. Scarano, and G. Filatrella. 2014. "How Quiz-Based Tools Can Improve Students' Engagement and Participation in the Classroom." In Proceedings of International Conference on Collaboration Technologies and Systems, 379-386, Minneapolis, MN, USA.

Morgan, R. 2008. "Exploring the Pedagogical Effectiveness of Clickers." InSight: A Journal of Scholarly Teaching 3: 31-36.

Prince, M. 2004. "Does Active Learning Work? A Review of the Research." Journal of Engineering Education 93: $223-231$.

Rossiter, J. 2014. "Using Clickers in Lectures to Help Identify and Teach the Control Topics Students Find Difficult." UKACC International Conference on Control, Loughborough, July 9-11.

Smith, M., W. Wood, W. Adams, C. Wieman, J. Knight, N. Guild, and T. T. Su. 2009. "Why Peer Discussion Improves Student Performance on In-class Concept Questions." Science 323: 122-124.

Snedecor, G., and W. Cochran. 1989. Statistical Methods. 8th ed. Ames: lowa State University Press.

Vernaza, K. 2007. 'Using Personal Response System Technology and Concept Check Modules to Improve Students' Learning Experience: A Case Study." 37th ASEE/IEEE Frontiers in Education Conference, Milwaukee, WI, October 10-13.

Zhu, E., C. Bierwert, and K. Bayer. 2007. "Qwizdom Student Survey." Unpublished raw data. 